\title{
0 inquérito nacional de soroprevalência de avaliação do controle da doença de Chagas no Brasil (2001-2008)
}

\author{
The National Survey of seroprevalence for evaluation of the control \\ of Chagas disease in Brazil (2001-2008)
}

\author{
Alejandro Luquetti Ostermayer*, Afonso Dinis Costa Passos**, Antônio Carlos Silveira***, \\ Antonio Walter Ferreira****, Vanize Macedo† e Aluízio Rosa Prata*****
}

\begin{abstract}
RESUMO
Um inquérito de soroprevalência de doença de Chagas foi realizado em amostra representativa da população com idade até cinco anos de toda a área rural brasileira, exceto o Estado do Rio de Janeiro. Foram estudadas 104.954 crianças, que tiveram amostras de sangue coletadas em papel de filtro e submetidas a testes de screening pelas técnicas de imunofluorescência indireta (IFI) e ELISA em um único laboratório. Todas as amostras com resultados positivos ou indeterminados, juntamente com $10 \%$ daquelas com resultados negativos, foram enviadas para um laboratório de referência e aí submetidas a novos testes por IFI e ELISA, além de western blot TESA (Trypomastigote Excreted Secreted Antigen). Para as crianças com resultado final positivo foi agendada uma re-visita para coleta de sangue venoso do próprio participante e das suas mães e familiares. Da avaliação do conjunto de testes resultaram $104(0,1 \%)$ resultados positivos, dos quais apenas $32(0,03 \%)$ foram confirmadas como infectadas. Destas, $20(0,02 \%)$ com positividade materna concomitante (sugerindo transmissão congênita), $11(0,01 \%)$ com positividade apenas na criança (indicativo de provável transmissão vetorial), e uma criança positiva cuja mãe havia falecido. Em 41 situações ocorreu confirmação apenas nas mães, sugerindo transferência passiva de anticorpos maternos; em 18 a positividade não se confirmou nem nas crianças nem nas suas mães; e em 13 não foi possível a localização de ambas. As 11 crianças que adquiriram a infecção por provável via vetorial distribuíram-se predominantemente na região nordeste (Piauí, Ceará, Rio Grande do Norte, Paraíba e Alagoas), acrescidas de um caso no Amazonas e um no Paraná. Dos 20 casos com provável transmissão congênita sobressaiu-se o Rio Grande do Sul, com $60 \%$ deles, representando este o primeiro relato de diferenças regionais na transmissão congênita da doença de Chagas no Brasil, possivelmente relacionada à existência de Trypanosoma cruzi grupo IId e IIe, atualmente classificados como TcV e TcVI. Os resultados deste inquérito apontam para a virtual inexistência de transmissão de doença de Chagas por via vetorial no Brasil em anos recentes, resultante da combinação dos programas regulares e sistemáticos de combate á moléstia e de mudanças de natureza socioeconômica observadas no país ao longo das últimas décadas. Por outro lado, reforçam a necessidade de manutenção de um programa de controle que garanta a consolidação deste grande avanço.
\end{abstract}

Palavras-chaves: Doença de Chagas. Inquérito. Soro-prevalência. Transmissão congênita. Crianças. Brasil.

\section{ABSTRACT}

A survey for seroprevalence of Chagas disease was held in a representative sample of Brazilian individuals up to 5 years of age in all the rural areas of Brazil, with the single exception of Rio de Janeiro State. Blood on filter paper was collected from 104,954 children and screened in a single laboratory with two serological tests: indirect immunofluorescence and enzyme linked immunoassay. All samples with positive or indetermined results, as well as $10 \%$ of all the negative samples were submitted to a quality control reference laboratory, which performed both tests a second time, as well as the western blot assay of TESA (Trypomastigote Excreted Secreted Antigen). All children with confirmed final positive result $(n=104$, prevalence $=0.1 \%)$ had a follow-up visit and were submitted to a second blood collection, this time a whole blood sample. In addition, blood samples from the respective mothers and familiar members were collected. The infection was confirmed in only $32(0.03 \%)$ of those children. From them, $20(0.025 \%)$ had maternal positive results, suggesting congenital transmission; 11 (0.01\%) had non-infected mothers, indicating a possible vectorial transmission; and in one whose mother had died the transmission mechanism could not be elucidated. In further 41 visited children the infection was confirmed only in their mothers, suggesting passive transference of maternal antibodies; in other 18, both child and mother were negative; and in 13 cases both were not localized. The 11 children that acquired the infection presumably through the vector were distributed mainly in the Northeast region of Brazil (States of Piauí, Ceará, Rio Grande do Norte, Paraíba and Alagoas), in addition to one case in Amazonas (North region) and another in Parana (South region). Remarkably, 60\% of the 20 cases of probably congenital transmission were from a single State, Rio Grande do Sul, with the remaining cases distributed in other states. This is the first report demonstrating regional geographical differences in the vertical transmission of Chagas disease in Brazil, which probably reflects the predominant Trypanosoma cruzi group IId and IIe (now TcV and TcVI) found in this state. Overall, these results show that the regular and systematic control programs against the transmission of Chagas disease, together with socioeconomic changes observed in Brazil in the last decades, interrupted the vectorial transmission in Brazil, resumed in the few cases found in this national survey. Furthermore they reinforce the need for maintenance of control programs for the consolidation of this major advance in public health.

Key-words: Chagas disease. Survey. Sero-prevalence. Congenital transmission. Children. Brazil.

*Laboratório de Doença de Chagas, Hospital das Clínicas, Universidade Federal de Goiás, Goiânia, GO. **Departamento de Medicina Social, Faculdade de Medicina de Ribeirão Preto, Universidade de São Paulo, Ribeirão Preto, SP. ***Ex Diretor da Divisão Nacional de Doença de Chagas do Ministério da Saúde e Consultor da Organização Panamericana de Saúde, Brasília, DF. ****Instituto de Medicina Tropical de São Paulo, Universidade de São Paulo, São Paulo, SP. *****Universidade Federal do Triangulo Mineiro, Uberaba, MG. †In memoriam. Endereço para correspondência: Dr. Alejandro Luquetti Ostermayer. Lab. de Chagas/Hospital das Clínicas/UFG. Caixa Postal 1.031, 74001-970 Goiânia, GO. e-mail: luquetti@hc.ufg.br

\section{INTRODUÇÃO}

Ações sistematizadas de controle da transmissão vetorial da doença de Chagas no país passaram a ser desenvolvidas em caráter regular, e com alcance nacional, a partir do ano de 1975. A cobertura integral da área então considerada endêmica, que compreendia $36 \%$ do território do país ${ }^{1}$, incluindo 2.136 municípios de 18 estados, se alcançou aproximadamente dez anos mais tarde, entre 1983 e 1984. Já então se admitia que a transmissão houvesse sido interrompida em 267 daqueles municípios endêmicos ${ }^{2}$. Progressivamente novas áreas foram 
sendo consideradas livres de transmissão, sempre com base em indicadores entomológicos de uso corrente, conhecidos a partir da própria rotina das operações de controle ${ }^{3-5}$.

O exame dos dados entomológicos, com o propósito de inferir sobre o corte de transmissão, deve compreender a análise de todo um conjunto de informações. Existe certa tendência em se estabelecer metas para o controle vetorial em termos de valores de infestação aceitáveis, como se a eles correspondessem à inviabilidade da transmissão. $\mathrm{Na}$ determinação do risco de transmissão, ademais da presença do vetor, que se traduz como indicador em taxa de infestação, importa considerar se os vetores presentes estão infectados, o que se expressa como índice tripano-triatomínico ou taxa de infecção; e, ainda, se existem colônias intradomiciliares, medida pelo número de unidades domiciliares com capturas de ninfas em relação ao total de unidades com o achado de triatomíneos. Outras variáveis, complementarmente, poderão ter importância, como a capacidade vetorial da(s) espécie(s) presente(s) e a densidade das populações remanescentes ${ }^{6}$.

Por mais que se apure a análise e por mais fiáveis que sejam os dados entomológicos, para a demonstração do corte de transmissão têm apenas valor prognóstico, ou de presunção de que novos casos de infecção humana, produzidos pelo vetor no ambiente domiciliar, já não ocorram.

A comprovação, de forma conclusiva, que a transmissão foi interrompida requer o estudo da infecção na população humana, em grupos etários jovens, ou seja, na população nascida após se haver admitido, a partir dos indicadores entomológicos mencionados, que a transmissão tenha sido detida ou seja improvável.

0 grupo de menores de 5 anos de idade é considerado o mais indicado para este tipo de estudo, sendo recomendado pela Organização Pan-Americana de Saúde (OPAS/OMS) para avaliações do gênero ${ }^{7}$. Idades menores podem não se prestar para esse propósito, porque nessa situação, em que a infestação será presumivelmente ou comprovadamente focal, uma vez ainda exista, a densidade das populações domiciliadas do vetor será mínima e, o mais das vezes, exclusivamente peridomiciliar. Isso implica que as possibilidades de transmissão sejam igualmente mínimas e que ocorra mais tardiamente, o que decorre das dificuldades inerentes ao próprio mecanismo de transmissão vetorial, que exige repetidos contatos entre o homem e o vetor infectado $0^{6,8}$.

Passados mais de vinte anos, desde quando inauguradas ações regulares de controle químico vetorial no país, havia que se promover um novo inquérito de soroprevalência de âmbito nacional. Nesse tempo, pontualmente, por iniciativa de um ou outro estado, foram feitos alguns inquéritos em escolares de 7 a 14 anos de idade, como parte das ações de vigilância epidemiológica em municípios considerados sem transmissão. Por facilidade operacional é que se tomou a população escolar, ainda que o formalmente recomendado, segundo as normas preconizadas pela Divisão de Doença de Chagas do Ministério da Saúde (DIDOCh/SUCAM/MS) fosse o grupo de 0 a 5 anos $^{9}$. Dados acumulados destes inquéritos mostraram uma proporção de soropositivos da ordem de $0,04 \%$ para o ano de $1999^{10}$. Esse dado evidentemente não pode ser tomado como válido para o país, já que corresponde a apenas uma parte daqueles municípios então sob vigilância.
Evidentemente, que na avaliação do impacto das atividades de controle é indispensável o cotejo dos resultados que se está aqui reportando com aqueles obtidos antes da instituição das medidas de controle. O Inquérito sorológico de prevalência da infecção chagásica no Brasil ${ }^{11}$, realizado entre 1975 e 1980, está se tomando como linha de base e parâmetro inicial de medida.

Quando concebido e desenhado o presenteinquérito, buscavase como objetivo mais geral avaliar o estado atual de transmissão da infecção/doença de Chagas na área rural brasileira, o que está além da avaliação do impacto das ações de controle exercidas. Isso porque espera-se que possa servir para reorientar as ações de controle, assumindo-se que houve importantes mudanças no nível e no padrão de transmissão vetorial da doença de Chagas no Brasil, entre as quais importa assinalar que: I) a transmissão pelo principal vetor, estritamente domiciliado, Triatoma infestans foi interrompida (formalmente certificada no ano de 2006 por comissão técnica designada pela OPAS/OMS ${ }^{12}$ ) e que a espécie está presente apenas em focos residuais de infestação no oeste do Estado da Bahia e noroeste do Estado do Rio Grande do Sul; II) vetores autóctones, antes considerados de importância secundária, como Panstrongylus megistus, Triatoma brasiliensis, Triatoma pseudomaculata e Triatoma sordida poderão estar ainda mantendo a transmissão domiciliar de T. cruzi em áreas de onde são nativos, sem que se saiba exatamente em que extensão e magnitude; III) algumas espécies que de inicio se considerava de hábitos exclusivamente silvestres têm sido com frequência capturadas no ambiente domiciliar, inclusive constituindo colônias intra-domiciliares, notadamente Panstrongylus lutzi na região nordeste e Triatoma rubrovaria no extremo sul; IV) casos de doença aguda vem sendo conhecidos em número crescente em áreas até há pouco consideradas indenes, relacionados diretamente ao ciclo enzoótico de transmissão e por meio de mecanismos que se julgava excepcionais ou de menor importância, como pela visitação reiterada dos vetores aos domicílios, por transmissão extra-domiciliar ou por transmissão oral, na qual o vetor em algum momento tem participação.

Para o esclarecimento dessas questões, o inquérito cujos resultados estão sendo aqui apresentados, certamente, contribuirá de forma determinante.

\section{OBJETIVOS}

o presente inquérito foi definido com o objetivo geral de avaliar o estado atual de transmissão da doença de Chagas na área rural brasileira. Seus objetivos específicos foram: A) estimar a soroprevalência da infecção chagásica humana na população de 0-5 anos de idade residente na área rural brasileira; B) avaliar o impacto havido na transmissão da infecção chagásica no país a partir do controle das populações domiciliadas de vetor, exercido de forma regular desde 1975.

\section{MÉTODOS}

\section{População alvo e população amostrada}

A população alvo foi constituída por crianças comidade entre zero e cinco anos incompletos, residentes na área rural brasileira. 
A população amostrada foi constituída por todas as localidades (unidades amostrais conglomeradas de segundo estágio) existentes nos municípios legalmente instalados no país (unidades amostrais conglomeradas de primeiro estágio).

\section{Plano amostral}

A inexistência de informações sobre as variâncias intra e entre municípios e intra e entre localidades, e a impossibilidade de sua produção através de uma investigação piloto, fez com que estes tamanhos de amostras fossem determinados a partir das frações amostrais de primeiro e de segundo estágio. Para isto, foi assumido que a amostragem fosse uma amostra casual simples de crianças, o que na realidade não ocorreria.

Considerando uma amostra casual simples, para estimar uma proporção $p$, com um erro relativo de estimação $\varepsilon$ e um fator de confiança $z$, desprezando-se o fator de correção para população finita, o número de crianças na amostra seria dado por:

$$
n \geq \frac{z^{2}(1-p)}{\varepsilon^{2} p}
$$

Foi possível estimar a existência de 4.707 .702 crianças com idade entre zero e cinco anos de idade residindo na área rural brasileira, utilizando-se as seguintes fontes: dados demográficos dos estados e regiões brasileiras, relativos ao Censo de $1991^{13}$; dados sobre a população geral de crianças de zero a cinco anos, relativos à Campanha Nacional de Vacinação Contra a Poliomielite, realizada no ano de 1999 (FUNASA, s/d); dados do Inquérito Sorológico Nacional de Doença de Chagas 1975/8011; e dados demográficos constantes do Anuário do IBGE $^{14}$.

A partir das informações obtidas por unidade federada no Inquérito de Soroprevalência de doença de Chagas realizado entre 1975 e $1980^{11}$, única fonte de dados para o país como um todo, e fazendo-se uma ponderação pelo número de municípios então existentes em cada unidade e um ajuste para a faixa etária de 0 a 5 anos de idade, foi possível assumir-se um valor de $p=0,001$ para a proporção populacional de soropositivos no país, nessa faixa etária.

Optou-se pela realização de uma amostragem aleatória independente para cada unidade federada, consideradas então como estratos; dentro delas foram escolhidas as amostras de grandes conglomerados, em dois estágios, sendo o primeiro representado por municípios e o segundo por localidades.

Fixando-se $p=0,001, \varepsilon=0,30$ e uma confiabilidade estatística de $95 \%$ (o que implica um valor de $z \approx 2$ ), chegouse ao número de 44.400 crianças. Devido a uma possível correlação intraclasse nos conglomerados, adotou-se um efeito de desenho igual a 3, o que elevou $n$ para 133.200. Como a amostra não era de crianças, o número destas ao final do estudo era uma quantidade aleatória, portanto imprevisível, a priori. Considerando-se ainda que as unidades amostrais de primeiro e segundo estágio tinham grande variabilidade no seu tamanho (em termos do número de crianças existentes), adotou-se um fator de segurança que consistiu na inflação de $10 \%$ para o valor de $n$, resultando o número previsível de crianças no estudo de 146.520 .
Como o tamanho estimado da população alvo era de 4.707.702, isto implicava uma fração amostral total, para o país, igual a $f=0,0311$. Tendo-se em conta a conveniência, manifestada pela Coordenação do Programa de Controle de Doença de Chagas, de incluir uma maior fração de municípios do que uma fração de localidades na amostra em cada estado optou-se por uma fração de municípios $(f 1)$ da ordem de 0,40 . Dessa maneira, a fração $f_{2}$ de localidades que melhor se acomodava à amostra autoponderada, isto é $f=f_{1} \times f_{2}$, seria $f_{2}=0,08$. Assim, $f$ foi reformulado para 0,032 , chegando-se a um valor aproximado de 150.646 participantes.

Em resumo, o plano de amostragem e os tamanhos amostrais adotados nesta investigação podem ser esquematizados da seguinte maneira: 1) estratificação do país por unidade federada (o Distrito Federal foi tomado como uma cidadeestado, merecendo, portanto, o mesmo tratamento dos demais estados); 2) amostragem aleatória independente, em cada unidade federada, de municípios (conglomerados de primeiro estágio) e localidades (conglomerados de segundo estágio) dentro dos municípios selecionados para a amostra;3) sendo Mo número de municípios numa dada unidade federada, o número $m$ de municípios dessa unidade na amostra foi dado por $m=f_{1}$ $\chi M$ (onde $f 1=0,40$ ). A amostra de municípios em cada unidade federada foi determinada previamente à realização do inquérito, através de uma amostragem sistemática obtida a partir de uma listagem por ordem alfabética dos municípios em cada estado; 4) sendo $L$ o número de localidades num dado município selecionado para a amostra, o número $l$ de localidades na amostra nesse município foi dado por $l=f_{2} \times L$ (onde $f_{2}=0,08$ ). A seleção foi feita por meio de uma amostragem sistemática a partir de uma lista de localidades em cada município, organizadas em ordem alfabética crescente e obtidas de reconhecimento geográfico atualizado; 5) uma vez selecionada uma dada localidade, todos os domicílios existentes nessa localidade e todas as crianças de 0 a 5 anos incompletos existentes nesses domicílios foram elegíveis para fazer parte do estudo.

Exceções a este plano geral foram feitas para alguns municípios amazônicos (Barcelos e Novo Airão, no Amazonas, Normandia e Bonfim, em Roraima, Santarém e todos os municípios da Ilha de Marajó, no Pará), com particularidades epidemiológicas que recomendavam a sua inclusão no estudo. Os seus resultados, contudo, foram tratados à parte e não incluídos no presente trabalho.

\section{Critérios de inclusão}

Foram incluídas no estudo todas as crianças com idade entre zero e cinco anos incompletos residentes nas localidades sorteadas, cujos pais ou responsáveis concordaram com a participação, após terem tomado conhecimento detalhado dos objetivos e da metodologia do estudo e terem assinado um termo de consentimento escrito.

No caso do responsável não ter condições de ler e/ou de assinar, o termo de consentimento foi lido por um dos membros da equipe, elucidando dúvidas eventualmente levantadas pelo pai ou responsável. Em tais casos, havendo concordância na participação, a mesma foi expressa mediante tomada das impressões digitais do polegar direito. 


\section{Organização dos trabalhos de campo}

Organização e projeto piloto

Por delegação do Ministério de Saúde e da Secretaria de Vigilância em Saúde, a coordenação do projeto esteve a cargo da Faculdade de Medicina da Universidade Federal do Triângulo Mineiro (FM/UFTM). Houve outros três centros de trabalho: Universidade de Brasília (UnB), onde foram digitadas as fichas com informações individuais; Laboratório de Pesquisa da doença de Chagas, da Faculdade de Medicina da Universidade Federal de Goiás (UFG), onde foram realizados todos os testes sorológicos; Instituto de Medicina Tropical de São Paulo, da Universidade de São Paulo (USP), onde foi realizado o controle laboratorial de qualidade. Para cada centro foram estabelecidos padrões e fluxos de trabalho ${ }^{15}$.

As atividades foram coordenadas a partir da FM/ UFTM, incluindo: coleta de amostras de sangue em campo, processamento de amostras (testes sorológicos de triagem (screening) e controle de qualidade), registro e processamento de dados; investigação de casos e tratamento específico dos casos confirmados como infectados. A sequência das operações obedeceu a fluxogramas previamente definidos ${ }^{15}$.

A partir do contato inicial com as Secretarias Estaduais de Saúde (SES), que deveriam indispensavelmente estar integradas ao projeto, e de sua aceitação em dele participar, a FM/FMTM assumia o compromisso de proporcionar capacitação e o suprimento de insumos para as atividades de coleta de amostras pelas equipes estaduais. As atividades foram planejadas em conjunto, por técnicos da coordenação central do projeto e da SES, seguindo as instruções de manual elaborado especificamente para a investigação ${ }^{15}$.

O laboratório da UFG recebia as amostras e formulários, processando as primeiras e encaminhando os segundos para digitação na UnB. Dez por cento das amostras recebidas, assim como as rotuladas como não negativas, foram encaminhadas para o laboratório da USP. Cada laboratório digitou os resultados no programa correspondente e encaminhou mensalmente os resultados para digitação.

O trabalho foi precedido por um estudo piloto realizado em novembro de 2001 no município de Ituiutaba, MG, onde foram coletadas as 40 amostras iniciais.

\section{Organização dos itinerários}

A estratégia de abordagem de cada estado obedeceu a condições similares de operação, dividindo o país nas seguintes regiões: área 1: Minas Gerais; área 2: Rio Grande do Sul, Santa Catarina, Paraná, e São Paulo; área 3: Rio de Janeiro, Espírito Santo e Bahia; área 4: Mato Grosso do Sul, Mato Grosso, Goiás, Distrito Federal, Tocantins e Maranhão; área 5: Pará, Amapá, Amazonas, Roraima, Acre e Rondônia; área 6: Sergipe, Alagoas, Pernambuco, Paraíba, Rio Grande do Norte, Ceará e Piauí.

\section{Emissão de etiquetas e identificação das amostras}

As etiquetas das localidades previamente selecionadas foram geradas na FM/UFTM, utilizando código de barras. Este foi construído com onze dígitos numéricos, sendo os dois primeiros para individualizar o estado (por exemplo,
31 para $\mathrm{MG}$ ), seguindo a codificação do Departamento de Cartografia da Diretoria de Geociências do IBGE ${ }^{16}$. Os seis dígitos seguintes individualizaram os municípios e localidades, e os três últimos a criança. Foram geradas etiquetas suficientes para a densidade populacional de cada localidade, em geral de menos de 100 números (por exemplo, para Ituiutaba: 31.340.000.001) para identificar a primeira criança. Para cada número foram geradas seis etiquetas, com as seguintes destinações: 1: papel de filtro com amostra de sangue; 2: formulário individual com os dados da criança; 3: eluato, no laboratório da UFG; 4: livro de registro do laboratório, junto com os resultados obtidos; 5 e 6: para encaminhamento ao laboratório da USP (uma afixada no papel de filtro com a segunda gota de sangue e outra para afixar no eluato).

\section{Coleta, armazenamento e envio das amostras de sangue}

Foram visitados todos os domicílios das localidades selecionadas, tendo sido incluídas como participantes todas as crianças que se enquadrassem nos critérios de inclusão. Enquanto um agente de saúde preenchia o formulário individual de coleta de dados, um enfermeiro procedia a coleta de duas gotas de sangue obtidas por punção digital, depositadas em áreas previamente desenhadas a lápis, em papel de filtro (Whatman $\mathrm{n}^{\circ}$ 1, Qualitative Filter Paper, cat. 1001110 lot H-718.100.111.01, Maidstone, England). O referido papel (suporte) foi adquirido com formato circular, com $11 \mathrm{~cm}$ de diâmetro, e dividido em três partes, cada uma delas destinada a tomada de sangue de uma criança.

o tamanho das gotas devia preencher todo o espaço previamente delimitado com compasso e lápis. Em cada papel foram desenhados dois círculos com $16 \mathrm{~mm}$ de diâmetro cada um, o que equivale a área de $2 \mathrm{~cm}^{2}$, ou seja, metade da área preconizada por Guimarães ${ }^{17}$. Ao adicionar $125 \mu$ l de diluente, obteve-se a diluição de 1:10 da gota inicial.

A identificação foi realizada imediatamente após a coleta, afixando a primeira das seis etiquetas com os códigos de barra numerados. A seguir foram preenchidos os dados da criança e dos pais, afixando a segunda etiqueta no formulário.

Após secagem, as amostras foram colocadas entre dois separadores de papel celofane ou plástico impermeável, e acondicionadas em caixa de isopor, à temperatura ambiente, por no máximo uma semana. As amostras foram encaminhadas semanalmente para o laboratório, pelos correios, em envelopes comuns, junto com as etiquetas não utilizadas e as fichas de cada criança devidamente preenchidas, assim como os termos de consentimento. Também foram incluídos os relatórios sucintos das atividades, contendo balanço da produção (total de amostras colhidas, localidades e casas visitadas, fechadas, desabitadas e com recusa), material utilizado e não utilizado, especialmente as etiquetas, assim como intercorrências e dificuldades encontradas.

\section{Processamento das amostras}

Fase de triagem (screening) em papel de filtro

Após a recepção no laboratório da UFG, de cada amostra foram checadas a data de encaminhamento, existência do formulário devidamente preenchido e o tamanho das gotas. 
As amostras foram armazenadas a $-20^{\circ} \mathrm{C}$, até o processamento, em geral no decorrer de sete dias. No dia anterior à execução dos testes, a primeira gota de sangue foi dividida ao meio e recortado o papel de filtro excedente. A metade de uso foi eluída com $62 \mu \mathrm{L}$ de solução salina tamponada, $\mathrm{pH}$ 7,0 e mantida a $4^{\circ} \mathrm{C}$ durante 14 a $16 \mathrm{~h}$ (overnight). A outra metade foi mantida a $-20^{\circ} \mathrm{C}$, para eventuais repetições.

A técnica de imunofluorescência indireta, segundo Camargo ${ }^{18}$, foi aplicada a cada amostra, utilizando $10 \mu \mathrm{L}$ de eluato no primeiro poço de cada lâmina, previamente sensibilizada com antígeno de cepa Y de Trypanosoma cruzi, diluindo com $10 \mu \mathrm{L}$ de tampão PBS (Phosphate Buffered Saline). Uma segunda diluição foi aplicada no poço seguinte, com $10 \mu \mathrm{L}$ da anterior, adicionada de $10 \mu \mathrm{L}$ de PBS. Cada eluato foi incubado na diluição final de $1 / 10 \mathrm{e}$ de $1 / 20$. Após incubação a $37^{\circ} \mathrm{C}$ durante $30 \mathrm{~min}$, as lâminas foram lavadas 3 vezes, com 10min em cada passo. Posteriormente foi adicionado o conjugado de anti-IgG humana com isotiocianato de fluoresceína, bioMerieux Brasil@, lotes 1202 (val. 01/07/2003) e 805717301 (val. 02/2008) e incubado a $37^{\circ} \mathrm{C}$ durante $30 \mathrm{~min}$. Foi posteriormente repetido o ciclo de três lavagens e montada cada lamina com glicerol tamponado, para proceder a sua leitura em microscópio de fluorescência Nikon Eclipse E200.

A validação de cada teste incluiu controles internos negativos (valor igual ou menor que 1/10) e positivos (resultado esperado 1/160 com variação de um titulo, ou seja, $1 / 80$ a $1 / 320$ ). Leituras de eluatos de $1 / 10$ ou < $1 / 10$ foram interpretadas como negativos e todo resultado positivo na diluição de $1 / 20$ foi repetido no dia seguinte, com diluições sequenciais de $1 / 10$ até $1 / 320$. Quando o resultado foi positivo apenas na diluição de $1 / 10$, o teste foi repetido. Todo eluato com resultado igual ou maior que $1 / 20$, na repetição, foi elegível para encaminhamento de duplicata para o laboratório da USP.

$O$ antígeno de cepa $Y$ de Trypanosoma cruzi, foi obtido a partir de cultivo em meio LIT (Liver Infusion Tryptose), mantido a $26^{\circ} \mathrm{C}$, em crescimento em fase logarítmica. A preparação do antígeno incluiu a fixação dos parasitos com formaldeido (Merck®) na proporção de $5 \%$, a $37^{\circ} \mathrm{C}$, durante 30 min e sucessivas lavagens. Uma vez determinada a concentração final, as lâminas foram sensibilizadas com os parasitos fixados, na quantidade de 10 a 50 por campo microscópico de 10 x 40.

O teste imunoenzimático de ELISA foi realizado em paralelo, em microplacas de polipropileno de 96 cavidades, de fundo plano, seguindo a técnica de Voller e cols ${ }^{19}$. Cada placa foi sensibilizada no dia anterior, com antígeno de cepa Y preparado anteriormente, com 10 a $15 \mu$ l de lisado do parasito por placa e diluído em tampão de cobertura (coating buffer), incubado a $4^{\circ} \mathrm{C}$. No dia do teste, cada placa foi lavada 5 vezes e coberta com Tween 20 e caseína durante $60 \mathrm{~min}$ a $37^{\circ} \mathrm{C}$. Após novo ciclo de lavagem, foi adicionado em cada poço o respectivo eluato, diluído 1:10 com PBS-tween-caseína e incubado $2 \mathrm{~h}$ a temperatura ambiente. Após novo ciclo de lavagem, foi adicionado o conjugado anti IgG humana com peroxidase (Sigma A6029, lotes 012k9167, val. 01/06/2004 e $124 \mathrm{k} 6017$ val. 30/06/2008) e nova incubação por $2 \mathrm{~h}$ a temperatura ambiente. Após lavagem, foi adicionado o substrato (orto-fenileno-di-amina e $\mathrm{H}^{2} \mathrm{O}^{2}$ ), incubado durante 30min em câmara obscura, com controle do desenvolvimento de cor. Para interromper a reação, foi utilizado ácido sulfúrico
$10 \mathrm{~N}$, e determinada a densidade ótica (DO) de cada poço por meio de espectrofotômetro Tecan Spectra, no comprimento de onda de 490nm.

Foram utilizados controles internos de soros e de eluatos em cada placa e determinado o ponto de corte pelo somatório da DO de dois controles positivos de baixa reatividade e dois controles negativos de elevada reatividade. Após validação do teste, a DO de cada amostra foi dividida pelo valor de DO de ponto de corte, obtendo um quociente que foi considerado não reagente quando menor que 0,9 indeterminado quando com valores entre 0,9 a 1,1 e reagente quando maior que $1,1^{20}$. Todos os eluatos com resultado indeterminado ou reagente foram repetidos no dia seguinte, para confirmação do resultado. Aqueles que forneceram resultado não negativo no segundo teste foram encaminhados para o laboratório de São Paulo.

os resultados de cada eluato foram classificados como positivos quando a IFI forneceu resultado de $1 / 80$ ou maior e a ELISA quociente de 1,2 ou maior. O resultado foi digitado como código 2 no banco de dados. Amostras com IFI reagente e ELISA negativo foram classificadas como discordantes e registrado o resultado como indeterminado, com código 3. Amostras com um resultado indeterminado também foram classificadas com código 3 e encaminhada a duplicata do papel de filtro para o laboratório de qualidade. Amostras com títulos de 1:10 ou menor na IFI e índice em ELISA < 0,9 foram consideradas negativas, e digitadas com o código 1.

\section{Controle de qualidade}

Todas as amostras com resultado não-negativo foram encaminhadas para o Laboratório da USP, assim como $10 \%$ das amostras negativas, representadas por aquelas com ultimo digito igual a 2 .

O encaminhamento foi mensal, contendo todas as amostras já processadas, com terminação em 2, e todas as não negativas. As remessas foram encaminhadas por correio Sedex, sem refrigeração, para o Laboratório da USP. Para isso foi encaminhada a metade não utilizada do papel de filtro contendo a amostra acompanhada da etiqueta com o código de barras. Este laboratório realizou um teste de IFI (conjunto diagnóstico bioMerieux ${ }^{\circledR}$ ), um teste de ELISA (conjunto diagnóstico bioMerieux ${ }^{\circledR}$ ) e o teste de western blot (TESAcruzi, desenvolvido e industrializado por bioMerieux Brasil ${ }^{21}$ ), para confirmação ou não do resultado.

Os resultados foram digitados pelo código de barra no programa utilizado pelos participantes deste estudo e também encaminhados a UnB.

Foram considerados positivos aqueles testes com TESAcruzi positivo, ou com IFI e ELISA positivos. No resultado final, foram considerados os cinco testes (dois no Laboratório da UFG e três no Laboratório da USP). Se dois deles foram positivos, em qualquer um dos dois laboratórios, o eluato foi catalogado como positivo, e a criança deveria ser visitada novamente, para elucidação diagnóstica.

\section{Revisita para coleta de sangue venoso}

Todas as crianças com resultado positivo ou indeterminado foram revisitadas para coleta de sangue venoso da criança e da sua mãe e coleta em papel de filtro dos familiares (irmãos, pai, e outros). Também foi solicitada aos técnicos a pesquisa de triatomíneos no intra e no peridomicílio. 0 
sangue foi colhido pelo sistema vacutainer $(\mathrm{BD} \AA)$, utilizando tubos com gel, que permitiram apenas a centrifugação na sede e o encaminhamento imediato das amostras para o laboratório, devidamente acondicionadas em caixas de isopor com refrigeração (gelo reciclável), despachadas pelo serviço Sedex. Além do material para coleta de sangue venoso, foram encaminhadas as etiquetas com o código de barras do município em questão e preenchidos formulários específicos para sangue venoso, assim como formulário de famílias, indicando o código de barras para cada familiar, o grau de parentesco e os correspondentes termos de consentimento.

No laboratório foram realizados testes de IFI e ELISA nas novas amostras de sangue assim como nos papeis de filtro com o sangue dos familiares. Também foram feitos nos soros o teste rápido PaGIA ${ }^{\circledR 22}$ e hemaglutinação indireta Wiener ${ }^{\circledR 23}$. Os soros foram também encaminhados para o Laboratório da USP, que realizou os mesmos testes que nos eluatos: IFI, ELISA e western blot (TESAcruzi).

Após a realização do estudo sorológico pelos Laboratórios da UFG e da USP, cada resultado foi classificado como segue: I) resultado positivo no papel de filtro confirmado pelo estudo do soro. Concluiu-se que é caso sorologicamente confirmado de infecção pelo Trypanosoma cruzi, susceptível a tratamento etiológico; II) resultado positivo no papel de filtro não confirmado pelo processamento das amostras com soro; tratase de falso positivo no papel de filtro, não confirmado pelo resultado no soro. III) resultado positivo no papel de filtro e indeterminado no soro. Foi interpretado como reação cruzada com outras doenças, como leishmaniose.

A coleta simultânea de sangue venoso da mãe permitiu ainda três possibilidades: A) no caso de confirmação da positividade na criança (situação I), com mãe também positiva, aventou-se a transmissão vertical, em particular se não havia relato de encontro de triatomíneos nem antecedentes de transfusão ou transplante na criança; B) se os resultados sorológicos obtidos da mãe fossem negativos, e a criança positiva, desde que maior de seis meses de idade, a possibilidade de transmissão vetorial deveria ser considerada; C) ainda, na situação II, criança com sangue venoso sem anticorpos, porém com mãe infectada, desde que na primeira coleta a criança fosse menor de seis meses de idade, a situação podia ser definida como transferência passiva de anticorpos maternos presentes na primeira coleta, porém desaparecendo após.

\section{Investigação de casos}

Após a confirmação sorológica, os casos de crianças com anticorpos anti-T. cruzi, foram visitados pela terceira vez, agora com equipe médica, visando realização de exame clinico, ECG, e eventual tratamento etiológico, se os pais estivessem de acordo. A equipe incluiu agentes de saúde para fazer a pesquisa entomológica, que foi estendida a domicílios próximos se comprovada a presença de triatomíneos no domicílio de onde procedia o caso sob investigação.

Para os casos tratados foi solicitado acompanhamento da correta administração do fármaco, por familiares, professora de escola ou líder comunitário, assim como contato com médico local para eventuais reações adversas.

\section{Análise estatística}

Associações entre variáveis qualitativas foram pesquisadas por meio dos testes qui-quadrado e exato de Fisher. As variáveis que mostraram um valor de $p$ igual ou inferior a 25\%, na análise univariada, foram posteriormente submetidas à análise multivariada, através da aplicação de um modelo log binomial. $O$ valor de $p=0,05$ foi considerado como limite para significância estatística ${ }^{24}$.

\section{Aspectos éticos}

O projeto foi submetido ao Comitê de Ética em Pesquisa da Faculdade de Medicina do Triângulo Mineiro (Protocolo 0142) e aprovado em nove de março de 2001.

\section{RESULTADOS}

As coletas de sangue por punção digital começaram em cinco de novembro de 2001 e finalizaram em 20 de maio de 2008, em 26 estados da federação, excluído apenas o Rio de Janeiro.

Dos 5.476 municípios existentes no Brasil, ao início do inquérito, foram incluídos 2.201 (40\%), aproximadamente a fração amostral planejada para o país e para cada uma das unidades federadas (Tabela 1).

A distribuição desses municípios é retratada na Figura 1, que mostra a sua ampla dispersão em todos os estados brasileiros.

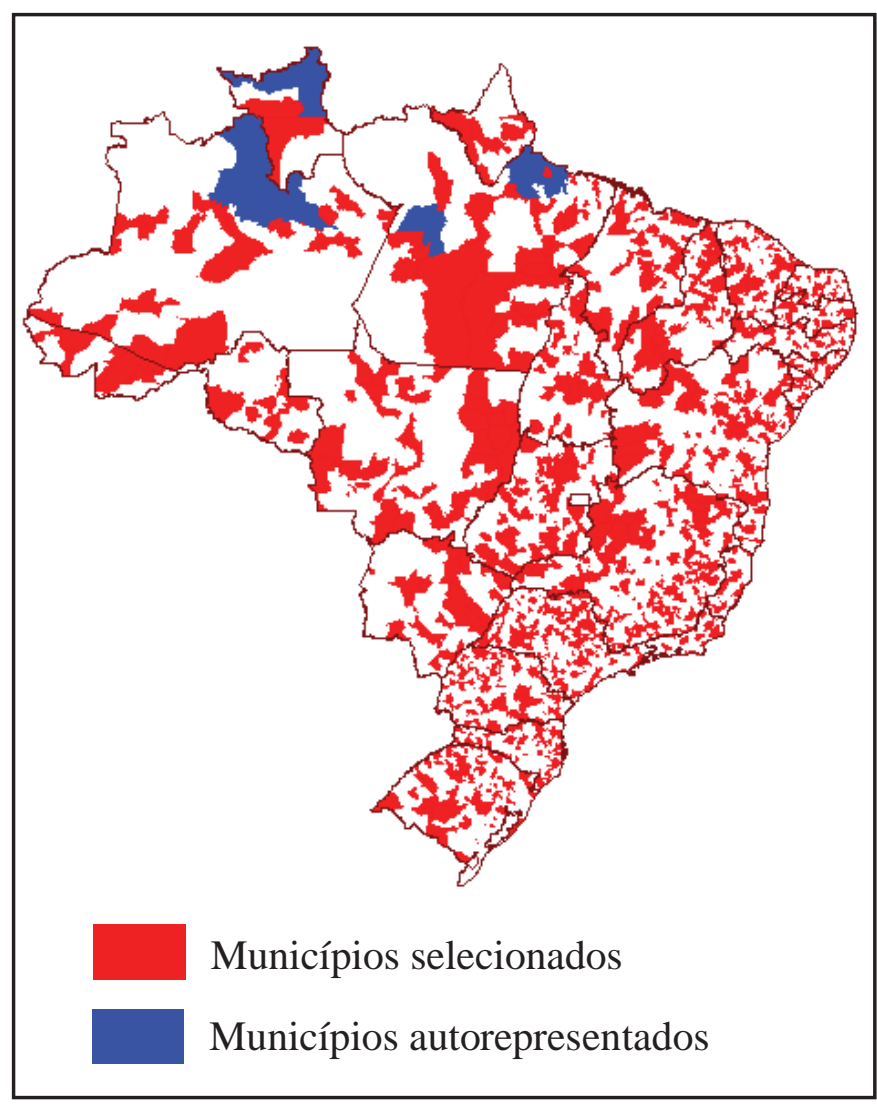

FIGURA 1 - Distribuição dos municípios sorteados para participação no estudo e dos municípios nele incluídos como auto-representados. Inquérito Nacional de Soroprevalência da Infecção Chagásica (INSIC), 2001-2008. 
TABELA 1 - Municípios existentes no Brasil e municípios selecionados para participação no estudo, segundo os Estados e as Regiões do País. Inquérito Nacional de Soroprevalência da Infecção Chagásica (INSIC). Brasil, 2001 - 2008.

\begin{tabular}{|c|c|c|c|}
\hline \multirow[b]{2}{*}{ Regiões/Estados } & \multicolumn{3}{|c|}{ Municípios } \\
\hline & existentes & selecionados & $\%$ \\
\hline \multicolumn{4}{|l|}{ Região Norte } \\
\hline Acre & 22 & 9 & 40,9 \\
\hline Amazonas & 62 & 25 & 40,3 \\
\hline Amapá & 16 & 6 & 37,5 \\
\hline Pará & 143 & 64 & 44,8 \\
\hline Rondônia & 52 & 21 & 40,4 \\
\hline Roraima & 15 & 7 & 46,7 \\
\hline Tocantins & 139 & 56 & 40,3 \\
\hline Total & 449 & 188 & 41,9 \\
\hline \multicolumn{4}{|l|}{ Região Nordeste } \\
\hline Maranhão & 217 & 87 & 40,1 \\
\hline Piauí & 221 & 89 & 40,3 \\
\hline Ceará & 184 & 73 & 39,7 \\
\hline Rio Grande do Norte & 166 & 65 & 39,2 \\
\hline Paraíba & 223 & 89 & 39,9 \\
\hline Pernambuco & 153 & 61 & 39,9 \\
\hline Alagoas & 101 & 41 & 40,6 \\
\hline Sergipe & 75 & 30 & 40,0 \\
\hline Bahia & 415 & 166 & 40,0 \\
\hline Total & 1.755 & 701 & 39,9 \\
\hline \multicolumn{4}{|l|}{ Região Centro-Oeste } \\
\hline Mato Grosso do Sul & 77 & 31 & 40,3 \\
\hline Mato Grosso & 126 & 50 & 39,7 \\
\hline Goiás & 242 & 97 & 40,1 \\
\hline Distrito Federal & 1 & 1 & 100,0 \\
\hline Total & 446 & 179 & 40,1 \\
\hline \multicolumn{4}{|l|}{ Região Sudeste } \\
\hline Minas Gerais & 852 & 341 & 40,0 \\
\hline Espírito Santo & 77 & 31 & 40,3 \\
\hline Rio de Janeiro & 91 & 37 & 40,7 \\
\hline São Paulo & 645 & 258 & 40,0 \\
\hline Total & 1.665 & 667 & 40,1 \\
\hline \multicolumn{4}{|l|}{ Região Sul } \\
\hline Paraná & 399 & 160 & 40,1 \\
\hline Santa Catarina & 293 & 118 & 40,3 \\
\hline Rio Grande do Sul & 469 & 188 & 40,1 \\
\hline Total & 1.161 & 466 & 40,1 \\
\hline Brasil & 5.476 & 2.201 & 40,2 \\
\hline
\end{tabular}

O plano amostral previa a inclusão de 150.549 participantes, tendo sido obtidas amostras de 105.813 crianças. Dessas, foram excluídas 265 por diversos motivos, sendo os mais frequentes representados por quantidade de amostra insuficiente ou sem condições de análise (presença de fungos, etc.) e falta da ficha correspondente. Posteriormente, foram excluídos os resultados de mais 594 crianças, por não preenchimento do critério de idade ou por falta de dados considerados imprescindíveis. O total de exclusões (859) representou 0,8\% do conjunto de coletas, resultando na amostra final de 104.954, ou $69,7 \%$ do total previsto no plano amostral. Por macro-regiões, os percentuais de coleta variaram de $50,8 \%$, no sul, a $78,7 \%$ no nordeste. Com exceção de três Estados (Acre, Roraima e Sergipe), onde a coleta superou o valor previsto, em todos os demais os percentuais ficaram abaixo de $100 \%$, com variações de 40,9\% no Paraná a 95,5\% no Ceará (Tabela 2).

A Tabela 3 mostra uma distribuição aproximadamente homogênea por sexo e faixa etária, embora com discreto predomínio do sexo masculino e das idades acima de dois anos.

Resultados reagentes para a infecção pelo T. cruzi foram observados em 104 participantes (Tabela 4), correspondendo a um percentual de $0,1 \%$. A distribuição nas diferentes categorias de positividade mostrou $41(0,04 \%)$ casos em que

TABELA 2 - Número de amostras previstas para coleta e de amostras examinadas segundo Regiões e Estados do Brasil. Inquérito Nacional de Soroprevalência da Infecção Chagásica (INSIC). Brasil, $2001-2008$.

\begin{tabular}{|c|c|c|c|}
\hline \multirow[b]{2}{*}{ Regiões/Estados } & \multicolumn{3}{|c|}{ Amostras } \\
\hline & previstas & examinadas & $\%$ \\
\hline \multicolumn{4}{|l|}{ Região Norte } \\
\hline Acre & 989 & 1.100 & 111,2 \\
\hline Amazonas & 3.857 & 1.678 & 43,5 \\
\hline Amapá & 456 & 258 & 56,6 \\
\hline Pará & 12.977 & 9.228 & 71,1 \\
\hline Rondônia & 2.142 & 1.014 & 47,3 \\
\hline Roraima & 393 & 431 & 109,7 \\
\hline Tocantins & 2.084 & 1.168 & 56,0 \\
\hline Total & 22.898 & 14.877 & 65,0 \\
\hline \multicolumn{4}{|l|}{ Região Nordeste } \\
\hline Maranhão & 13.737 & 9.049 & 65,9 \\
\hline Piauí & 4.874 & 3.581 & 73,5 \\
\hline Ceará & 10.264 & 9.797 & 95,5 \\
\hline Rio Grande do Norte & 3.156 & 1.750 & 55,4 \\
\hline Paraíba & 4.544 & 2.991 & 65,8 \\
\hline Pernambuco & 8.480 & 7.132 & 84,1 \\
\hline Alagoas & 4.927 & 3.723 & 75,6 \\
\hline Sergipe & 2.287 & 2.552 & 111,6 \\
\hline Bahia & 20.244 & 16.489 & 81,5 \\
\hline Total & 72.513 & 57.064 & 78,7 \\
\hline \multicolumn{4}{|l|}{ Região Centro-Oeste } \\
\hline Mato Grosso do Sul & 1.541 & 927 & 60,2 \\
\hline Mato Grosso & 2.425 & 1.776 & 73,2 \\
\hline Goiás & 3.266 & 1.877 & 57,5 \\
\hline Distrito Federal & 443 & 323 & 72,9 \\
\hline Total & 7.675 & 4.903 & 63,9 \\
\hline \multicolumn{4}{|l|}{ Região Sudeste } \\
\hline Minas Gerais & 14.881 & 11.210 & 75,3 \\
\hline Espírito Santo & 2.494 & 1.885 & 75,6 \\
\hline Rio de Janeiro & 2.174 & - & - \\
\hline São Paulo & 8.308 & 5.058 & 60,9 \\
\hline Total & 27.857 & 18.153 & 65,2 \\
\hline \multicolumn{4}{|l|}{ Região Sul } \\
\hline Paraná & 8.349 & 3.412 & 40,9 \\
\hline Santa Catarina & 4.777 & 2.016 & 42,2 \\
\hline Rio Grande do Sul & 6.480 & 4.529 & 69,9 \\
\hline Total & 19.606 & 9.957 & 50,8 \\
\hline Brasil & 150.549 & 104.954 & 69,7 \\
\hline
\end{tabular}


TABELA 3 - Distribuição da população estudada segundo faixa etária e sexo. Inquérito Nacional de Soroprevalência da Infecção Chagásica (INSIC). Brasil, $2001-2008$

\begin{tabular}{|c|c|c|c|c|c|c|c|c|}
\hline \multirow[b]{3}{*}{ Faixa etária } & \multicolumn{6}{|c|}{ Sexo } & & \\
\hline & \multicolumn{2}{|c|}{ masculino } & \multicolumn{2}{|c|}{ feminino } & \multicolumn{2}{|c|}{ ignorado } & \multicolumn{2}{|c|}{ total } \\
\hline & $\mathrm{n}^{\circ}$ & $\%$ & $\mathrm{n}^{\circ}$ & $\%$ & $\mathrm{n}^{\circ}$ & $\%$ & $\mathrm{n}^{\circ}$ & $\%$ \\
\hline $0 \mid-1$ & 9.666 & 18,0 & 9.050 & 17,7 & 43 & 16,3 & 18.759 & 17,9 \\
\hline $1 \mid-2$ & 10.476 & 19,5 & 9.923 & 19,5 & 51 & 19,3 & 20.450 & 19,5 \\
\hline $2 \mid-3$ & 11.190 & 20,8 & 10.603 & 20,8 & 46 & 17,4 & 21.839 & 20,8 \\
\hline $3 \mid-4$ & 10.951 & 20,4 & 10.550 & 20,7 & 50 & 18,9 & 21.551 & 20,5 \\
\hline $4 \mid-5$ & 11.151 & 20,8 & 10.664 & 20,9 & 50 & 18,9 & 21.865 & 20,8 \\
\hline Ignorada & 259 & 0,5 & 207 & 0,4 & 24 & 9,1 & 490 & 0,5 \\
\hline Total & 53.693 & 100,0 & 50.997 & 100,0 & 264 & 100,0 & 104.954 & 100,0 \\
\hline
\end{tabular}

o resultado foi confirmado nas mães, porém com os filhos mostrando sorologia negativa nos exames realizados em sangue obtido por punção venosa. Esta situação foi mais frequentemente observada nos Estados da Bahia (8), Rio Grande do Sul (8) e Minas Gerais (20). Em 20 (0,02\%) situações, a positividade foi confirmada tanto nas mães quanto nas crianças, chamando a atenção que 12 delas ocorreram no Rio Grande do Sul. Em 18 (0,02\%), ocorreu o contrário, ou seja, em nenhuma delas os resultados positivos foram confirmados. Em 13 participantes, não foi possível localizar mãe e criança, e em um caso o participante foi confirmado como positivo, porém sua mãe havia falecido. Crianças positivas com mães negativas, situação indicativa de provável transmissão vetorial, ocorreram em 11 participantes, representando um percentual de $0,01 \%$. Estes 11 casos se distribuíram por sete estados, sendo nove crianças positivas identificadas na região nordeste, uma no Amazonas e uma no Paraná. Portanto, $32(0,03 \%)$ participantes na faixa etária de até cinco anos apresentaram sorologia positiva confirmada para infecção chagásica, representados pelos 11 da categoria 2, acrescidos dos 20 da categoria 3 e do único incluído na categoria 4 (Tabela 4).

A distribuição destes 32 casos positivos de acordo com a faixa etária e o sexo mostrou um predomínio masculino (19 contra 13) e presença da infecção em todas as idades, mais acentuadamente entre os 3 e 4 anos. Estas diferenças, todavia, não se mostraram significativas do ponto de vista estatístico (Tabela 5).

TABELA 4 - Distribuição dos participantes segundo grandes regiões/ estados e categoria de positividade nos testes de screening e nos testes confirmatórios. Inquérito Nacional de Soroprevalência da Infecção Chagásica (INSIC). Brasil, 2001 - 2008.

\begin{tabular}{|c|c|c|c|c|c|c|c|c|}
\hline $\begin{array}{l}\text { Categoria* } \\
\text { Região/UF }\end{array}$ & 1 & 2 & 3 & 4 & 5 & 6 & Negativos & Total \\
\hline \multicolumn{9}{|l|}{ Norte } \\
\hline Acre & - & - & 1 & - & - & 2 & 1.097 & 1.100 \\
\hline Amazonas & - & 1 & - & - & - & - & 1.677 & 1.678 \\
\hline Amapá & - & - & - & - & 1 & - & 257 & 258 \\
\hline Pará & - & - & - & - & - & 2 & 9.226 & 9.228 \\
\hline Rondônia & - & - & - & - & - & - & 1.014 & 1.014 \\
\hline Roraima & - & - & - & - & - & - & 431 & 431 \\
\hline Tocantins & - & - & - & - & - & - & 1.168 & 1.168 \\
\hline Total & - & 1 & 1 & - & 1 & 4 & 14.870 & 14.877 \\
\hline \multicolumn{9}{|l|}{ Nordeste } \\
\hline Maranhão & 1 & - & - & - & 1 & - & 9.047 & 9.049 \\
\hline Piauí & - & 2 & - & - & & - & 3.579 & 3.581 \\
\hline Ceará & - & 2 & - & - & 2 & 2 & 9.791 & 9.797 \\
\hline R. G. do Norte & - & 1 & - & - & 1 & - & 1.748 & 1.750 \\
\hline Paraíba & - & 2 & - & - & & 1 & 2.988 & 2.991 \\
\hline Pernambuco & 2 & - & 1 & - & 1 & - & 7.128 & 7.132 \\
\hline Alagoas & 1 & 2 & 1 & - & 1 & - & 3.718 & 3.723 \\
\hline Sergipe & - & - & - & - & & - & 2.552 & 2.552 \\
\hline Bahia & 8 & - & 1 & 1 & 6 & 1 & 16.472 & 16.489 \\
\hline Total & 12 & 9 & 3 & 1 & 12 & 4 & 57.023 & 57.064 \\
\hline \multicolumn{9}{|l|}{ Centro-Oeste } \\
\hline M. G. do Sul & 1 & - & - & - & & 1 & 925 & 927 \\
\hline Mato Grosso & - & - & - & - & & - & 1.776 & 1.776 \\
\hline Goiás & - & - & - & - & & - & 1.877 & 1.877 \\
\hline Distrito Federal & - & - & - & - & & - & 323 & 323 \\
\hline Total & 1 & 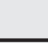 & & 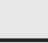 & & 1 & 4.901 & 4.903 \\
\hline \multicolumn{9}{|l|}{ Sudeste } \\
\hline Minas Gerais 2 & 20 & - & 3 & - & 2 & 3 & 11.182 & 11.210 \\
\hline Espírito Santo & - & - & - & - & & - & 1.885 & 1.885 \\
\hline São Paulo & - & - & - & - & & 1 & 5.057 & 5.058 \\
\hline Total & 20 & & 3 & & 2 & 4 & 18.124 & 18.153 \\
\hline \multicolumn{9}{|l|}{ Sul } \\
\hline Paraná & - & 1 & 1 & - & & - & 3.410 & 3.412 \\
\hline Santa Catarina & - & - & - & - & 1 & - & 2.015 & 2.016 \\
\hline R. G. do Sul & 8 & - & 12 & - & 2 & - & 4.507 & 4.529 \\
\hline Total & 8 & 1 & 13 & & 3 & & 9.932 & 9.957 \\
\hline Brasil & 41 & 11 & 20 & 1 & 18 & 13 & 104.954 & 104 \\
\hline
\end{tabular}

TABELA 5 - Distribuição dos participantes com positividade isolada ou em conjunto com positividade materna, segundo faixa etária e sexo. Inquérito Nacional de Soroprevalência da Infecção Chagásica (INSIC). Brasil, 2001 - 2008.

\begin{tabular}{|c|c|c|c|c|c|c|c|c|c|}
\hline \multirow[b]{3}{*}{ Faixa etária } & \multicolumn{6}{|c|}{ Sexo } & \multirow{2}{*}{\multicolumn{3}{|c|}{ Total }} \\
\hline & \multicolumn{3}{|c|}{ Masculino } & \multicolumn{3}{|c|}{ Feminino } & & & \\
\hline & positivos & total & $\%$ & positivos & total & $\%$ & positivos & total & $\%$ \\
\hline $0 \mid-1$ & 2 & 9.666 & 0,02 & 4 & 9.050 & 0,04 & 6 & 18.716 & 0,03 \\
\hline $1 \mid-2$ & 2 & 10.476 & 0,02 & 1 & 9.923 & 0,01 & 3 & 20.399 & 0,01 \\
\hline $2 \mid-3$ & 2 & 11.190 & 0,02 & 4 & 10.603 & 0,04 & 6 & 21.793 & 0,03 \\
\hline $3 \mid-4$ & 8 & 10.951 & 0,07 & 2 & 10.550 & 0,02 & 10 & 21.501 & 0,05 \\
\hline $4 \mid-5$ & 5 & 11.151 & 0,04 & 2 & 10.664 & 0,02 & 7 & 21.815 & 0,03 \\
\hline Total & 19 & 53.434 & 0,04 & 13 & 50.790 & 0,03 & 32 & 104.224* & 0,03 \\
\hline
\end{tabular}

*Excluídos 730 participantes por falta de informações relativas à faixa etária, sexo ou ambos. 
A Tabela 6 retrata a positividade em relação a algumas características domiciliares. Os maiores percentuais de positividade foram observados nas residências com paredes de madeira, com cobertura de zinco, quando havia animais domésticos no intradomicílio e na presença de triatomíneos, tanto no intra quanto no peridomicílio. Cotejando-se estes percentuais com a somatória das demais possibilidades, dentro de cada categoria de características domiciliares, a análise estatística revelou associação significativa para o tipo de paredes $(p=0,012)$ e presença de animais domésticos $(0,023)$, situando-se no limiar da significância para a existência de triatomíneos no intradomicílio $(0,054)$.

Uma análise multivariada realizada pelo método log binomial mostrou associação estatística independente entre presença de infecção e as variáveis paredes de madeira $(p<0,001)$, animais domésticos no intradomicílio $(p=0,031)$ e triatomíneos no intradomicílio $(\mathrm{p}=0,012)$.

A Tabela 7 mostra a distribuição das crianças com sorologia positiva e das situações em que apenas a mãe revelou-se infectada, nas regiões norte e nordeste e nos seus respectivos estados e municípios.

Os mesmos achados, agora para as regiões centro-oeste, sudeste e sul, são mostrados na Tabela 8. Positividade apenas materna ocorreu em todas as regiões, com exceção do norte, com o número de casos atingindo valores mais elevados nos municípios de Porteirinha, São João da Ponte e Ubaí, todos em
TABELA 6 - Distribuição dos participantes com positividade isolada ou em conjunto com positividade materna, segundo algumas características dos domicílios em que residiam. Inquérito Nacional de Soroprevalência da Infecção Chagásica (INSIC), 2001 - 2008.

\begin{tabular}{|c|c|c|c|c|}
\hline \multirow[b]{2}{*}{ Características do domicílio } & \multicolumn{2}{|c|}{ Sorologia positiva } & \multirow[b]{2}{*}{ Total } & \multirow[b]{2}{*}{$\mathrm{p}$} \\
\hline & $\mathrm{n}^{\circ}$ & $\%$ & & \\
\hline \multicolumn{5}{|l|}{ Paredes } \\
\hline alvenaria & 16 & 0,02 & 65.943 & \\
\hline madeira & 13 & 0,07 & 17.913 & \\
\hline pau a pique & 2 & 0,02 & 10.796 & 0,012 \\
\hline outras/ignorada & 1 & 0,01 & 10.302 & \\
\hline \multicolumn{5}{|l|}{ Cobertura } \\
\hline telha & 27 & 0,03 & 87.881 & \\
\hline zinco & 2 & 0,08 & 2.644 & \\
\hline palha & 1 & 0,01 & 9.065 & \\
\hline outra/ignorada & 2 & 0,04 & 5.364 & 0,290 \\
\hline \multicolumn{5}{|c|}{ Animais domésticos no intradomicílio } \\
\hline $\operatorname{sim}$ & 23 & 0,05 & 50.414 & \\
\hline não & 9 & 0,02 & 48.234 & \\
\hline não sabe/ignorado & - & - & 6.306 & 0,023 \\
\hline \multicolumn{5}{|c|}{ Triatomíneos no peridomicílio } \\
\hline $\operatorname{sim}$ & 5 & 0,05 & 10.175 & \\
\hline não & 25 & 0,03 & 78.456 & \\
\hline não sabe/ignorado & 2 & 0,01 & 16.323 & 0,225 \\
\hline \multicolumn{5}{|c|}{ Triatomíneos no intradomicílio } \\
\hline $\operatorname{sim}$ & 8 & 0,06 & 12.421 & \\
\hline não & 22 & 0,03 & 76.834 & \\
\hline não sabe/ignorado & 2 & 0,01 & 15.699 & 0,054 \\
\hline Total & 32 & 0,03 & 104.954 & \\
\hline
\end{tabular}

TABELA 7 - Distribuição dos participantes com positividade isolada ou em conjunto com positividade materna, segundo estado, município de residência e a categoria de positividade para doença de Chagas nas regiões Norte e Nordeste. Inquérito Nacional de Soroprevalência da Infecção Chagásica (INSIC). Brasil, 2001 - 2008.

\begin{tabular}{|c|c|c|c|c|c|}
\hline $\begin{array}{l}\text { Categoria } \\
\text { Região/UF/Município }\end{array}$ & & Apenas mãe + & Apenas criança + & Mãe + e criança + & $\begin{array}{c}\text { Criança + } \\
\text { e mãe não localizada }\end{array}$ \\
\hline \multicolumn{6}{|l|}{ Norte } \\
\hline Acre & Cruzeiro do Sul & & & 1 & \\
\hline Amazonas & Juruá & & 1 & & \\
\hline \multicolumn{6}{|l|}{ Nordeste } \\
\hline Maranhão & Riachão & 1 & & & \\
\hline \multirow[t]{2}{*}{ Piauí } & Cap. Gervásio Oliveira & & 1 & & \\
\hline & Elesbão Veloso & & 1 & & \\
\hline \multirow[t]{2}{*}{ Ceará } & Quixelo & & 1 & & \\
\hline & Quixerê & & 1 & & \\
\hline R. Grande do Norte & Varzea & & 1 & & \\
\hline \multirow[t]{2}{*}{ Paraíba } & Emas & & 1 & & \\
\hline & Jerico & & 1 & & \\
\hline \multirow[t]{3}{*}{ Pernambuco } & Flores & 1 & & & \\
\hline & São José do Belmonte & 1 & & & \\
\hline & Panelas & & & 1 & \\
\hline \multirow[t]{2}{*}{ Alagoas } & Igaci & 1 & 2 & & \\
\hline & Matriz de Camaragibe & & & 1 & \\
\hline \multirow[t]{8}{*}{ Bahia } & Boa Vista do Tupim & 2 & & \multirow{8}{*}{1} & \multirow{8}{*}{1} \\
\hline & Campo Formoso & 1 & & & \\
\hline & Cariranha & 1 & & & \\
\hline & Correntina & 2 & & & \\
\hline & Esplanada & & & & \\
\hline & Maragogipe & & & & \\
\hline & Ruy Barbosa & 1 & & & \\
\hline & Serra do Ramalho & 1 & & & \\
\hline
\end{tabular}


Minas Gerais, com três ocorrências cada. Já para a situação de positividade tanto nas mães quanto nas crianças, destaca-se a concentração em municípios do Rio Grande do Sul, com ocorrência detectada em nove deles, incluindo três casos em São Sepé. Positividade apenas nas crianças foi detectada em dez municípios, sendo oito no nordeste, um no Amazonas e um no Paraná (Tabelas 7 e 8).

Uma caracterização mais detalhada destes 11 casos de positividade apenas nas crianças pode ser vista na Tabela 9. Observa-se ocorrência de dois casos nos Estados do Piauí, Ceará, Paraíba e Alagoas, porém apenas neste último isto ocorreu em um único município, (Igaci), mesmo que em localidades diferentes (Mata Amarela e Sitio Dionizão). Em nove situações, verifica-se que, embora nem sempre o município de nascimento corresponda àquele de residência, as faixas de tempo de vida e de moradia no local onde a amostra foi colhida são iguais, sinalizando para a possibilidade de que a infecção tenha ocorrido na própria localidade onde o participante foi identificado. As únicas exceções em relação a esta coincidência de tempo de vida e de residência foram verificadas no caso detectado na localidade de Mata Amarela, município de Igaci e no caso de Juruá, Amazonas. No primeiro, os achados mostram que a criança migrou de Novo Lino para Igaci, enquanto no segundo, ela permaneceu no mesmo município (Juruá), embora tendo mudado para uma localidade diferente daquela onde ocorreu o nascimento (Tabela 9).

TABELA 8 - Distribuição dos participantes com positividade isolada ou em conjunto com positividade materna, segundo estado município de residência e a categoria de positividade para doença de Chagas nas regiões Centro-Oeste, Sudeste e Sul. Inquérito Nacional de Soroprevalência da Infecção Chagásica (INSIC). Brasil, 2001 - 2008.

\begin{tabular}{|c|c|c|c|c|c|}
\hline $\begin{array}{l}\text { Categoria } \\
\text { Região/UF/Município }\end{array}$ & & Apenas mãe + & Apenas criança + & Mãe + e criança + & $\begin{array}{c}\text { Criança + } \\
\text { e mãe não localizada }\end{array}$ \\
\hline $\begin{array}{l}\text { Centro-Oeste } \\
\text { Mato Grosso do Sul }\end{array}$ & Nova Alvorada do Sul & 1 & & & \\
\hline 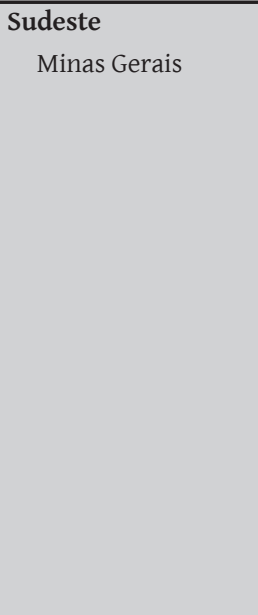 & $\begin{array}{l}\text { Capitão Enéas } \\
\text { Catuti } \\
\text { Chapada do Norte } \\
\text { Claro dos Poções } \\
\text { Francisco Sá } \\
\text { Mateus Leme } \\
\text { Pai Pedro } \\
\text { Pedra Azul } \\
\text { Porteirinha } \\
\text { Rio Pardo de Minas } \\
\text { São João da Ponte } \\
\text { São Joaquim de Bicas } \\
\text { Serranópolis de Minas } \\
\text { Ubai }\end{array}$ & $\begin{array}{l}1 \\
2 \\
1 \\
1 \\
1\end{array}$ & & $\begin{array}{l}1 \\
\\
1 \\
1\end{array}$ & \\
\hline $\begin{array}{l}\text { Sul } \\
\text { Paraná }\end{array}$ & $\begin{array}{c}\text { Antonio Olinto } \\
\text { Carlópolis }\end{array}$ & & 1 & 1 & \\
\hline 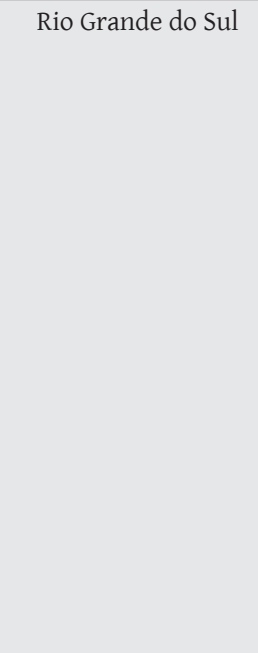 & $\begin{array}{c}\text { Alecrim } \\
\text { Cristal } \\
\text { Dom Pedrito } \\
\text { Entre-Ijuis } \\
\text { Erval Seco } \\
\text { Girua } \\
\text { Humaitá } \\
\text { Inhacora } \\
\text { Novo Cabrais } \\
\text { Paraíso do Sul } \\
\text { Porto Vera Cruz } \\
\text { Redentora } \\
\text { Santa Maria } \\
\text { Santiago } \\
\text { São Sepé } \\
\text { Vale do Sol }\end{array}$ & $\begin{array}{l}1 \\
1 \\
1 \\
\\
1 \\
1 \\
1 \\
1 \\
1\end{array}$ & & $\begin{array}{l}1 \\
\\
1 \\
2 \\
1 \\
1 \\
\\
1 \\
1 \\
3 \\
1\end{array}$ & \\
\hline
\end{tabular}


TABELA 9 - Distribuição dos onze participantes com sorologia positiva exclusivamente em si próprios segundo faixa etária, sexo, locais de nascimento e de residência e tempo em que reside no local em que a coleta de sangue foi realizada. Inquérito Nacional de Soroprevalência da Infecção Chagásica (INSIC). Brasil, 2001 - 2008.

\begin{tabular}{|c|c|c|c|c|c|c|c|c|}
\hline \multirow[b]{2}{*}{ Amostra } & \multirow{2}{*}{$\begin{array}{c}\text { Faixa etária } \\
\text { (anos) }\end{array}$} & \multirow[b]{2}{*}{ Sexo } & \multicolumn{2}{|c|}{ Nascimento } & \multicolumn{4}{|c|}{ Residência } \\
\hline & & & Estado & Município & Estado & Município & Localidade & Tempo (anos) \\
\hline 13022070005 & $3 \mid-4$ & $\mathrm{~F}$ & $\mathrm{AM}$ & Juruá & AM & Juruá & Caititu & $2 \mid-3$ \\
\hline 22024550019 & $0 \mid-1$ & M & PI & São João do Piauí & PI & Cap. Gervásio Oliveira & Aldeia & $0 \mid-1$ \\
\hline 22035030039 & $2 \mid-3$ & $\mathrm{~F}$ & PI & Elesbão Veloso & PI & Elesbão Veloso & Várzea Linda & $2 \mid-3$ \\
\hline 23113550007 & $4 \mid-5$ & M & $\mathrm{CE}$ & Orós & $\mathrm{CE}$ & Quixelo & Vassouras & $4 \mid-5$ \\
\hline 24147040005 & $2 \mid-3$ & M & RN & Várzea & RN & Várzea & Chuá & $2 \mid-3$ \\
\hline 25059070036 & $1 \mid-2$ & M & $\mathrm{PB}$ & Emas & PB & Emas & Fazenda Exu & $1 \mid-2$ \\
\hline 25074080016 & $4 \mid-5$ & M & $\mathrm{PB}$ & Pombal & PB & Jerico & Faz. Alto Alegre & $4 \mid-5$ \\
\hline 27031060033 & $4 \mid-5$ & M & $\mathrm{AL}$ & Novo Lino & $\mathrm{AL}$ & Igaci & Mata Amarela & $2 \mid-3$ \\
\hline 27031060123 & $3 \mid-4$ & M & $\mathrm{AL}$ & Arapiraca & $\mathrm{AL}$ & Igaci & Sítio Dionizão & $3 \mid-4$ \\
\hline 41013090009 & $2 \mid-3$ & M & PR & Antonio Olinto & PR & Antonio Olinto & Sitio Gadonski & $2 \mid-3$ \\
\hline
\end{tabular}

\section{DISCUSSÃO}

O inquérito nacional de soroprevalência de doença de Chagas buscou verificar a efetividade das medidas de controle entomológico implementadas no Brasil nas últimas décadas, utilizando para isso a estratégia de estudar crianças com idade inferior a cinco anos de idade, consideradas como indicador da situação atual de transmissão vetorial. A sua realização representou um enorme esforço para um grande número de pessoas envolvidas nos trabalhos de planejamento e de execução de todas as tarefas previstas, sejam elas relativas à coleta das amostras, sejam relativas à execução dos exames laboratoriais. Com efeito, um inquérito desenhado para incorporar cerca de 150 mil crianças até a idade de cinco anos incompletos, moradoras de áreas rurais de 2.200 municípios brasileiros, representa um desafio logístico considerável. Como pontos de destaque na qualidade desta investigação, merecem serem mencionados os cuidados na definição do plano amostral, a capacitação padronizada das equipes de campo e o rigor na realização das técnicas laboratoriais, fatores que certamente contribuíram para a qualidade dos dados obtidos. Indicativos disso podem ser encontrados no reduzido número de participantes descartados por problemas técnicos decorrentes da coleta e do transporte das amostras, assim como nos baixos percentuais de informações demográficas que não puderam ser utilizadas por não terem sido adequadamente coletadas e/ou digitadas. Como principal limitação, deve ser mencionada a não-participação do Estado do Rio de Janeiro, ausente em decorrência de limitações de natureza operacional e do baixo nível de prioridade conferido à doença de Chagas naquele estado, justificável, em parte, pela sua limitada importância como problema de saúde pública.

Em relação ao número de amostras previstas, o percentual de coleta foi de $69,7 \%$. Embora tenham ocorrido diferenças entre os estados, com valores mais elevados no nordeste e no norte, na maioria deles o numero foi menor que o previsto. As principais razões para isto podem ser encontradas no esvaziamento demográfico das áreas rurais ocorrido nos últimos anos no Brasil, tanto em decorrência da redução de fecundidade - observada de modo especial nas áreas mais desenvolvidas do país - como, especialmente, do intenso movimento migratório rural-urbano verificado no Brasil nas últimas quatro décadas. Com graus variados entre as diferentes regiões, observou-se um grande número de domicílios desabitados ou sem crianças na faixa etária requerida, em particular nos estados das regiões centro-oeste, sudeste e sul. Ilustrativo disso é o fato que, dos 258 municípios sorteados no Estado de São Paulo, em 26 (10,1\%) deles não foi encontrada nenhuma criança na faixa etária de interesse do inquérito.

Em razão do tamanho amostral do presente inquérito ser apenas um décimo daquele utilizado entre 1975 e $1980^{11}$, foi possível realizar todos os testes em um único laboratório, assegurando homogeneidade dos resultados. Ainda mais, facilitou a utilização de dois testes por amostra, em contraste com o inquérito anterior, que usou apenas uma técnica (IFI). Deve ser acrescentado que o controle de qualidade incluiu o envio a um segundo laboratório de referência de $10 \%$ de todas as amostras negativas, assim como todas as não negativas.

Tendo como base os resultados obtidos nos testes sorológicos em papel de filtro, a positividade global foi de 104 amostras em 104.954, ou seja, 0,099\%. Este valor difere substancialmente do verificado no inquérito conduzido entre 1975-1980, antes da implementação rotineira das medidas de controle, época em que a endemia chagásica encontrava-se amplamente disseminada em extensas áreas do território brasileiro ${ }^{11}$.

Após a confirmação dos resultados positivos em papel de filtro essas crianças foram revisitadas, ocasião em que foi colhido sangue venoso delas e das respectivas mães e familiares. Esta segunda visita foi possível em 91 (87,5\%) crianças. Nas 13 restantes, a família não foi localizada por diversas razões, especialmente mudança de domićlílo. Em 18 (19,8\%) destas 91 crianças verificou-se negatividade no sangue venoso da criança e da mãe, caracterizando um falso resultado positivo em papel de filtro. Esta situação já foi relatada em outros estudos ${ }^{25,26}$, exigindo confirmação em sangue venoso nos casos não negativos. A situação contrária, correspondente a falsos negativos, não inspira maiores preocupações por dois motivos: re-exame em laboratório de referência de $10 \%$ das amostras negativas e elevado valor preditivo negativo decorrente da baixíssima prevalência da infecção chagásica na população estudada. 
Em 40,1\% das crianças revisitadas ( $\mathrm{n}$ - $=41)$ o resultado em sangue venoso foi negativo, porem o soro da mãe confirmou a infecção pelo T. cruzi. Ao verificar a idade das crianças na época em que foi realizada a primeira coleta, todas se encontravam com quatro meses de idade ou menos, caracterizando transmissão passiva de anticorpos maternos. A predominância desses casos nos Estados de Minas Gerais (20), Rio Grande do Sul (8) e Bahia (8) reflete a distribuição da doença de Chagas no Brasil nas décadas anteriores, traduzida pelos percentuais de infecção observados no inquérito de 1975-1981, de 8,8\% nos dois primeiros e de 5,4\% na Bahia.

Situação diferente foi observada em 20 (22\%) casos, onde houve confirmação da existência da infecção tanto na mãe, como na criança. A idade destas crianças por ocasião da segunda coleta foi sempre superior a seis meses, o que afasta a possibilidade de transmissão passiva, haja vista que os títulos obtidos nos cinco testes sorológicos foram elevados, tanto nas crianças como nas mães. Na virtual ausência de outros mecanismos, tal situação aponta para uma possível transmissão vertical. Isto é reforçado pela ausência de sinais de colonização por vetores nos domicílios visitados, bem como pela negativa de antecedentes de transfusões ou transplantes nas crianças envolvidas ${ }^{27}$.

A distribuição destes casos classificados como provavelmente congênitos teve características peculiares: a maioria (12) foi encontrada apenas no Estado do Rio Grande do Sul, enquanto os demais distribuíram-se em seis diferentes unidades federadas: três casos em Minas Gerais e um nos Estados do Acre, Alagoas, Pernambuco, Bahia e Paraná. No Rio Grande do Sul foram examinadas 4.529 amostras, sendo que 12 (0,265\%) tiveram este mecanismo de transmissão. Em Minas Gerais, das 11.210 amostras coletadas, ocorreram 3 (0,027\%) casos de transmissão congênita. Nos demais estados, os percentuais de ocorrência deste tipo de transmissão variaram de 0,006\% na Bahia, a 0,029\% no Paraná, com valores de 0,091\% no Acre, 0,027\% em Alagoas e 0,014\% em Pernambuco. Assim, transmissão por provável via congênita no Rio Grande do Sul mostrou-se muito mais comum do que nos demais estados onde este mecanismo parece ter se feito presente, correspondendo a mais de nove vezes o observado no Paraná e a mais de 44 vezes o verificado na Bahia.

Este é o primeiro relato de diferenças regionais na transmissão congênita da doença de Chagas no Brasil, e pode estar relacionado à existência, no Rio Grande do Sul, de T. cruzi grupo IId e IIe, atualmente classificados como $\mathrm{TcV}$ e TcVI ${ }^{28}$. Estas linhagens são habitualmente responsáveis pelas infecções por T. cruzi no Uruguai, Argentina, Chile, Paraguai e Bolívia, onde se observam taxas relativamente elevadas de transmissão congênita. Em contrapartida, o T. cruzi IIb, atualmente classificado como TcII e habitualmente isolado no Brasil Central ${ }^{29}$, é associado ao megaesôfago, frequente nessa região, onde a prevalência da transmissão congênita é, reconhecidamente, mais baixa que nos outros países do cone sul. Esta observação inédita relaciona as cepas existentes no Rio Grande do Sul àquelas de circulação habitual no Uruguai e em outros países fronteiriços. Interessante assinalar que em região limítrofe com o Brasil (Departamento de Artigas, no Uruguai), Sarasúa ${ }^{30}$ já havia relatado elevada frequência desta modalidade de transmissão.
Em um caso do município de Maragogipe, Bahia, área de elevada endemicidade de doença de Chagas, a criança foi confirmadamente positiva, porém, a mãe havia falecido de causa não revelada, não sendo possível afastar a possibilidade de que ela também fosse infectada. Na hipótese desse ter sido também um caso de transmissão congênita, o percentual da Bahia passaria a ser de $0,012 \%$, similar ao verificado nos demais estados anteriormente referidos, exceção feita ao Rio Grande do Sul.

Em apenas $11(12,1 \%)$ casos, dentre os 91 onde foi possível a revisita, houve positividade em sangue venoso da criança, porém com ausência de infecção pelo T. cruzi nas respectivas mães, aventando a possibilidade de transmissão vetorial. Nove deles concentraram-se na região nordeste, nos municípios de Gervásio de Oliveira e Elesbão Veloso, no Piauí, Quixelo e Quixeré no Ceará, Emas e Jerico na Paraíba, Igaci em Alagoas e Várzea no Rio Grande do Norte. A ocorrência desses casos provavelmente esteja associada à transmissão domiciliar por espécies nativas de triatomíneos que têm comportamento ubíquo, com grande ecletismo alimentar, e podendo por isso colonizar, indiferentemente, a casa e seus anexos peridomiciliares. Pelos dados colhidos ao longo dos últimos dez anos (2001 a 2009), foram identificados nos municípios do Ceará (Quixelo e Quixeré), pela ordem de frequência de capturas, Triatoma brasiliensis, T. pseudomaculata $e$ Rhodnius nasutus, com o achado ocasional de Panstrongylus lutzi e de P. megistus. Aquelas duas primeiras espécies foram também encontradas nos municípios do Piauí (Capitão Gervásio Oliveira e Elesbão Veloso) e Paraíba (Emas e Jericó). No município de Várzea, no Rio Grande do Norte, o achado de Rhodius nasutus, ainda que não confirmado, poderia ser aventado pela constância em que é a espécie capturada na região. Em Igací, no Estado de Alagoas, houve a captura reiterada de $T$. pseudomaculata e de $P$. megistus.

Os outros dois casos de provável transmissão vetorial, dos municípios de Juruá (Amazonas) e Antonio Olindo (Paraná), para os quais não se conhece a existência de triatomíneos domiciliados, poderão ter ocorrido por visitação de vetores silvestres. Outra possível explicação para sua ocorrência seria a transmissão acidental por outras vias, como a transmissão vetorial extradomiciliar, e menos provavelmente por via oral.

Portanto, o percentual de positividade comprovada de crianças infectadas atingiu 0,03\% (32/104.954), sendo 20 (0,02\%) por provável transmissão congênita e $11(0,01 \%)$ por provável transmissão vetorial. Estes dados apontam no sentido de uma alteração relativa na importância dos mecanismos de transmissão no Brasil como um todo.

A análise multivariada revelou que presença de animais domésticos e de triatomíneos no intradomicílio, bem como existência de paredes de madeira, têm um papel preditor independente no risco de infecção entre as 32 crianças com positividade confirmada. Conquanto isso seja bastante intuitivo em relação à convivência próxima com animais domésticos e com vetores da doença de Chagas, a associação com paredes de madeira não encontra, à primeira vista, uma explicação palpável. Este dado deve ser visto com reservas, uma vez que a sistemática de coleta de informações previa apenas a descrição do material de que eram feitos os domicílios, sem entrar em detalhes sobre as suas condições de construção e/ou de conservação. 
O principal achado deste inquérito, contudo, foi a raridade da presença da infecção chagásica em crianças com idade até cinco anos, em toda a área rural brasileira. Tendo-se em conta que esta faixa etária presta-se bem à avaliação da ocorrência de transmissão em período recente, os resultados aqui descritos permitem concluir pela sua virtual inexistência no que tange à via vetorial no Brasil. Este achado, por si só, é extremamente auspicioso e representa um marco considerável para a saúde pública brasileira, para o qual contribuíram de modo decisivo os programas de combate instituídos de modo sistemático em todo o Brasil a partir de 1983. Claro está que a tais programas não pode ser atribuída a totalidade dos méritos pela virtual interrupção da transmissão, uma vez que eventos de natureza social e econômica verificados em décadas recentes no Brasil seguramente tiveram um peso considerável para este desfecho. Entre eles, a urbanização acelerada dos últimos 40 anos, esvaziando as áreas rurais e, consequentemente, reduzindo o contingente de pessoas expostas ao risco de infecção ${ }^{31}$. Paralelamente, há que se considerar também alguns avanços na melhoria das condições gerais de vida de segmentos populacionais menos favorecidos economicamente, processo este em curso desde o início da década de 1990.

Mesmo reconhecendo a complexidade e multiplicidade dos fatores envolvidos, não se pode deixar de reconhecer que programas de controle baseados no combate sistemático de triatomíneos têm, inquestionavelmente, um impacto importante nos níveis de transmissão da doença de Chagas. Isto acontece porque a redução dos níveis de infestação domiciliar de triatomíneos até um limiar crítico, mesmo sem que ocorra a sua eliminação completa do interior das habitações, tem como consequência a interrupção de transmissão. Tal fato é bem conhecido e pode ser ilustrado pela evolução da doença de Chagas em Cássia dos Coqueiros, Estado de São Paulo, onde borrifações de inseticidas levadas a efeito no início da década de 1960 acabaram por eliminar a transmissão, muito embora continuassem sendo descritos níveis reduzidos de triatomíneos no interior dos domicílios ${ }^{32}$.

A não inclusão do Estado do Rio do Janeiro, embora lamentável no conjunto do inquérito, não representa risco de comprometer os achados aqui discutidos, uma vez que a transmissão autóctone da doença de Chagas naquele estado nunca alcançou magnitude suficiente para classificá-lo como área de risco relevante.

Este enorme avanço verificado no controle da doença de Chagas no Brasil mostra a factibilidade de se interromper a transmissão domiciliar endêmica, com a eliminação de espécies alóctones de vetor e a manutenção das casas livres de colônias de vetores autóctones, para as quais é esse o nível máximo de controle que se pode pretender. A transmissão que tem origem diretamente no ciclo enzoótico (vetorial extradomiciliar ou por visitação e oral) será sempre uma possibilidade, uma vez que, como enzootia, a doença de Chagas não é erradicável.

\section{AGRADECIMENTOS}

Os autores agradecem a colaboração das seguintes instituições: Secretarias Estaduais de Saúde, Universidade Federal do Triangulo Mineiro, Núcleo de Medicina Tropical da Universidade de Brasília,
Universidade Federal de Goiás, Departamento de Medicina Social da Faculdade de Medicina de Ribeirão Preto e Instituto de Medicina Tropical de São Paulo, Universidade de São Paulo.

\section{SUPORTE FINANCEIRO}

Trabalho financiado pelo Ministério da Saúde.

\section{REFERÊNCIAS}

1. Marques AC. Controle de vetores da doença de Chagas. Experiência do Ministério da Saúde, Brasil. In: Coletânea SUCAM, editores. Brasília: Ministério da Saúde e Superintendência de Campanhas de Saúde Pública; 1979.

2. Superintendência de Campanhas de Saúde Pública e Ministério da Saúde. Controle de Endemias em 1983. 1ª ed. Brasília: Ministério da Saúde; 1983.

3. Dias JCP, Silveira AC, Schofield CJ. The Impact of Chagas disease Control in Latin América. A Review. Mem Inst Oswaldo Cruz 2002; 97:603-612.

4. Silveira AC, Rezende DF. Epidemiologia e controle da transmissão vetorial da doença de Chagas no Brasil. Rev Soc Bras Med Trop 1994; 27 (supl III):11-12.

5. Silveira AC, Vinhaes MC. Elimination of vector-borne trasmission of Chagas' disease. Mem Inst Oswaldo Cruz 1999; 94 (supl I):405-411.

6. Silveira AC. Profilaxia. In: Brener Z, Andrade Z, Barral-neto M, editores. Trypanosoma cruzi e Doença de Chagas. $2^{\mathrm{a}}$ ed. Rio de Janeiro: GuanabaraKoogan; 1999. p.75-87.

7. Organización Panamericana de la Salud. Guía de Evaluación de los procesos de control de triatominos y del control de la transmisión transfusional de T. cruzi. Montevideo: Organización Panamericana de la Salud; 2002.

8. Rabinovich JE, Wisnivesky-Colli C, Solarz ND, Gurtler RE. Probability of transmission of Chagas disease by Triatoma infestans (Hemiptera: Reduviidae) in an endemic area of Santiago del Estero, Argentina. Bull World Health Org 1990; 68:737-746.

9. Ministério da Saúde, Superintendência de Campanhas de Saúde Pública e Divisão de Doença de Chagas. Manual de Normas Técnicas da Campanha de Controle da Doença de Chagas. $1^{\mathrm{a}}$ ed. Brasília: Centro de Documentação do Ministério da Saúde; 1980.

10. Moncayo A, Silveira AC. Current epidemiological trends of Chagas disease in Latin America and future challenges: epidemiology, surveillance and health policies. Mem Inst Oswaldo Cruz 2009; 104 (suppl 1):17-30.

11. Camargo ME, Silva GR, Castilho EA, Silveira AC. Inquérito sorológico da prevalência de infecção chagásica no Brasil, 1975/1980. Rev Inst Med Trop São Paulo 1984; 26:192-204.

12. Pan American Health Organization [Internet]. XVI Reunión de la Comisión Intergubernamental de la Iniciativa del Cono Sur. Brasilia. Junio de 2007. Disponível em: www.paho.org/spanish/ad/dpc/cd/dch-incosur-xv.htm/.

13. Fundação Instituto Brasileiro de Geografia e Estatística. Censo demográfico de 1991. Disponível em: http \\www.ibge.gov.br/.

14. Instituto Brasileiro de Geografia e Estatística. Anuário estatístico do Brasil 1995. Rio de Janeiro: Instituto Brasileiro de Geografia e Estatística; 1996.

15. Inquérito Nacional de soroprevalência da infecção chagásica. Desenho do estudo, planejamento, operação; 2001.

16. Instituto Brasileiro de Geografia e Estatística e Diretoria de Geociências. Noções básicas de Cartografia. Rio de Janeiro: Instituto Brasileiro de Geografia e Estatística; 1998.

17. Guimarães MCS. Chagas' disease serology: specifications and evaluation methods for immunological reagents. Washington, DC: Pan American Health Organization; 1984.

18. Camargo ME. Fluorescent antibody test for the diagnosis of American trypanosomiasis. Technical modification employing preserved culture forms of Trypanosoma cruzi in a slide test. Rev Inst Med Trop São Paulo 1966; 8:227-234.

19. Voller A, Draper C, Bidwell DE, Bartlett A. A microplate enzyme-linked immunosorbent assay (ELISA) for Chagas disease. Lancet 1975; 1:426-429. 
20. Zicker F, Smith PG, Luquetti AO, Oliveira OS. Mass screening for Trypanosoma cruzi infections using the immunofluorescence, ELISA and haemagglutination tests on serum samples and on blood eluates from filter-paper. Bull World Health Org 1990; 68:465-471.

21. Umezawa ES, Nascimento MS, Kesper Jr N, Coura JR, Borges-Pereira J, Junqueira ACV, et al. Immunoblot assay using excreted-secreted antigens of Trypanosoma cruzi in serodiagnosis of congenital, acute, and chronic Chagas' disease. J Clin Microbiol 1996; 34:2143-2147.

22. Rabelo A, Luquetti AO, Moreira EF, Gadelha MF, Santos JA, Melo L, et al. Serodiagnosis of Trypanosoma cruzi Infection using the new particle gel immunoassay - ID-PaGIA Chagas. Mem Inst Oswaldo Cruz 1999; 94:77-82.

23. CerisolaJA, Chaben MF, Lazarijo. Test de hemaglutinación para el diagnóstico de la enfermedad de Chagas. Prensa Med Argent 1962; 49:1761-1767.

24. Skov T, Deddens J, Petersen MR, Endahl I. Prevalence proportion ratios estimation and hypothesis testing. Int J Epidemiol 1998; 27:91-95.

25. Zicker F, Oliveira RM, Luquetti AO, Smith PG. Seroprevalence of Trypanosoma cruzi infection among unskilled urban workers in central Brazil. Trans Roy Soc Trop Med Hyg 1989; 83:511-513.

26. Andrade ALSS, Zicker F, Oliveira RM, Silva SA, Luquetti AO, Travassos LR, et al. Randomized trial of efficacy of benznidazole in treatment of early Trypanosoma cruzi infection. Lancet 1996; 348:1407-1413.
27. Luquetti AO, Ferreira AW, Oliveira RA, Tavares SBN, Rassi A, Dias JCP, et al. Congenital transmission of Trypanosoma cruzi in Brazil: estimation of the prevalence based on preliminary results of the national serological survey in small children of 5 years, and other sources. Rev Soc Bras Med Trop 2005; 38 (supl 2):24-26.

28. Zingales B, Andrade SA, Briones MRS, Campbell DA, Chiari E, Fernandes O, et al. A new consensus for Trypanosoma cruzi intraspecific nomenclature: second revision meeting recommends TcI to TcVI. Mem Inst Oswaldo Cruz 2009; 104:1051-1054.

29. Luquetti AO, Miles MA, Rassi A, de Rezende JM, de Souza AA, Povoa MM, et al. Trypanosoma cruzi: zymodemes associated with acute and chronic Chagas'disease in central Brazil. Trans Roy Soc Trop Med Hyg 1986; 80:462-470.

30. Sarasúa WM. Detección de la transmission congénita de la enfermedad de Chagas en Artigas-Uruguay. Rev Soc Bras Med Trop 1993; 26(supl II):28.

31. Silva LJ. A evolução da doença de Chagas no Estado de São Paulo. [Tese de Doutorado]. [São Paulo]: Editora Hucitec; 1999.

32. Passos ADC, Nogueira JL, FigueiredoJFC, Gomes UA, Dalfabro AL. Evolução da positividade sorológica para doença de Chagas numa comunidade rural brasileira. Rev Panam Salud Publ 1997; 2:247-252. 